\title{
Use of Ash-and-Slag Wastes after Burning of Fine-Dispersed Coal-Washing Wastes
}

\author{
Vasilii Murko ${ }^{1 *}$, Veniamin Khyamyalyainen ${ }^{1}$, and Marina Baranova ${ }^{2}$ \\ ${ }^{1}$ T.F. Gorbachev Kuzbass State Technical University, 65000028 Vesennya st., Kemerovo, Russian \\ Federation \\ ${ }^{2}$ FSBEI HE "Krasnoyarsk SAU", Power Systems Department, 660130 Stasovoy St., Krasnoyarsk, \\ Russian Federation
}

\begin{abstract}
Effective utilization of ash-and-slag waste generated by coalfired power plants can help significantly to reduce the negative impact on the environment and improve their economic performance. Studies have been made of the mineralogical composition of ash-and-slag wastes obtained after the combustion of water-coal fuel based on fine-dispersed coal-washing waste (filter cake) in a specially designed boiler with a vortex combustion system. The possibility of effective use of ash-and-slag wastes for the production of building materials, primarily mortar mixes, widely used for mining works on mine openings, laying the worked out space, etc. (high content of silicon oxide and aluminum oxide is combined with a low carbon content in other words a negligible unburned carbon loss). The optimum percentage ratio of the initial components of the filling mixture based on ash-and-slag wastes and crushed rock (granulated slag) has been established. The results of experimental tests of hardening tabs on the strength under uniaxial compression are presented. It has been established that a sample containing $18 \%$ of ash-and-slag wastes, $33 \%$ of a granulated slag and $19 \%$ of cement, corresponds to the required technological parameters for the strength and cement content.
\end{abstract}

\section{Introduction}

The problem of industrial energy waste has become today one of the most important environmental problems faced by humankind. Largely, the problem is associated with large volumes of ash-and-slag waste (ASW) produced during the combustion of coal. The development of energy production technologies has made our life comfortable, but led to the fact that ASW will remain in the sedimentation tanks, hydro-dumps or on slime grounds for tens and hundreds of years. Effective utilization of ash from coal-fired power plants can help significantly to reduce the negative impact on the environment and improve their economic performance. Russia has the world's second-largest explored coal reserves. Every year, coal energy produces more than 75 million tons of ash-and-slag waste, of which about 11 percent is recycled, mainly in the form of secondary building materials [14].

${ }^{*}$ Corresponding author: sib eco@mail.ru 
At the same time, technologies and technical support for burning solid fuels are being improved. KuzSTU (Kemerovo) together with the companies SPC "Sibekotehnika" and "Teplotron" (Novokuznetsk) developed, manufactured and tested a boiler with a thermal capacity of $0.63 \mathrm{MW}$ with a vortex combustion system that efficiently operates on high-ash fuel, prepared on the basis of a filter-cake. In accordance with the tasks of experimental research, suspended water coal fuel (WCF), prepared on the basis of fine-dispersed coalwashing waste (FDCWW) from the coal-preparation plant's (CPP) "named after Kirov" and "Komsomolets" mines, was burned in a vortex furnace at an experimental stand. When burning WCF on the basis of fine coal waste in boilers of small and medium capacity, due to the high ash content of the fuel used, a significant amount of ash and slag wastes is formed. Fly ash (up to 50\%), carried away from the furnace with hot flue gases is trapped in the dust collector, and the remaining ash part in the form of slag falls on the grate. Under such conditions, the difference in the chemical-mineralogical composition of fly ash from the chemical-mineralogical composition of the ash of the initial fuel is insignificant [5-7].

However, the complexity of the composition of the mineral part of fossil coals, as well as the variety of forms of its connection with the organic mass, causes great difficulties in the analytical determination of the mineral components in the coals. Therefore, the content of minerals in coal is most often judged indirectly - by the quantity and quality of the ash, obtained by calcination to a constant mass of a sample of fuel in the presence of oxygen at $815 \pm 10{ }^{\circ} \mathrm{C}$ (GOST 11022-95). Coals ash often contain valuable, essential for the national economy substances. Therefore, the study of the mineral composition of the ash of produced coal is of great importance for the selection of options for their integrated and rational use.

The aim of the work was to determine the possibility of efficient use of ash-and-slag wastes generated by the combustion of water-coal fuel on the basis of fine waste from coalpreparation plants in small and medium-sized boilers to produce building materials, primarily hardening mortar mixes for mining.

\section{The study of the mineralogical composition of ASW}

An XRF-1800 scanning (single-channel) spectrometer (Shimadzu, Japan) with an x-ray tube with a rhodium anode of $40 \mathrm{kV}$ and a current of $95 \mathrm{~mA}$ was used to estimate the composition of the ash obtained after burning the filter cake samples. The counting time for all elements is $552 \mathrm{~s}$, while the calculation was carried out by the method of fundamental parameters.

When preparing the sample for X-ray fluorescence analysis, powdered ash samples were subjected to grinding in a vibration shaker, then pressed into a tablet on a press in a boric acid substrate.

The registration was performed with $\mathrm{K}_{\alpha}$-lines, the detector for Ti-U scintillation, for $K$, $\mathrm{Ca}, \mathrm{Sn}-\mathrm{Cs}, \mathrm{Cl}, \mathrm{S}, \mathrm{P}, \mathrm{Si}, \mathrm{Al}, \mathrm{Mg}, \mathrm{Na}, \mathrm{F}$ for flow, for Ti-U and $\mathrm{K}, \mathrm{Ca}, \mathrm{Sn}-\mathrm{Cs}$ - crystal $\mathrm{LiF}$, for $\mathrm{Ci}, \mathrm{S}, \mathrm{P}$ - crystal $\mathrm{Ge}$, for $\mathrm{Si}$, $\mathrm{Al}$ - crystal PET, for $\mathrm{Mg}, \mathrm{Na}, \mathrm{F}$ crystal TAP, aperture - $30 \mathrm{~mm}$, with sample rotation and evacuation of test chamber.

To evaluate the results of the analysis, the fundamental parameters were calculated, for which the analytical lines of all components of the sample were recorded, taking into account the background, and were calculated by the iteration method. The calculation is included in the XRF-1800 X-ray fluorescence spectrometer software.

Table 1 summarizes the mineral composition of the investigated filter cake samples.

As can be seen from Table 1, from the point of view of the chemical composition, the main component of the ash is silicon oxide $\mathrm{SiO}_{2}(59.83 ; 62.06 \%)$. Further in the composition of the ash there are oxides: aluminum $\mathrm{Al}_{2} \mathrm{O}_{3}(20.0 ; 21.03 \%)$, calcium $\mathrm{CaO}$ (4.64; 4.81\%), iron $\mathrm{Fe}_{2} \mathrm{O}_{3}(3.61 ; 3.20 \%)$, potassium $\mathrm{K}_{2} \mathrm{O}(3.25 ; 3.73 \%)$, magnesium $\mathrm{MgO}$ 
$(1.45 ; 1.42 \%)$, sodium $\mathrm{Na}_{2} \mathrm{O}(1.70 ; 1.58 \%)$. In addition to the listed oxides, other oxides with a content of less than $1.0 \%\left(\mathrm{TiO}_{2}, \mathrm{BaO}, \mathrm{SrO}, \mathrm{MnO}, \mathrm{CuO}\right)$ and less than $0.1 \%\left(\mathrm{Co}_{2} \mathrm{O}_{3}\right.$, $\mathrm{ZnO}, \mathrm{Rb}_{2} \mathrm{O}, \mathrm{Cr}_{2} \mathrm{O}_{3}, \mathrm{NiO}$ ) are present in a small amount in the mineral part. The mass fraction of elements $(\mathrm{P}, \mathrm{S}, \mathrm{C})$ in the ash is less than $1.0 \%$.

Table 1. The composition of the mineral part of the ash obtained from the combustion of FDCWW.

\begin{tabular}{|c|c|c|c|c|c|}
\hline \multirow[t]{2}{*}{ Elements } & \multicolumn{2}{|c|}{$\begin{array}{c}\text { Mass fraction of chemical } \\
\text { elements, } \%\end{array}$} & \multirow[t]{2}{*}{ Elements } & \multicolumn{2}{|c|}{$\begin{array}{c}\text { Mass fraction of chemical } \\
\text { elements, \% }\end{array}$} \\
\hline & $\begin{array}{l}\text { CPP "named } \\
\text { after S.M. } \\
\text { Kirov" mine }\end{array}$ & $\begin{array}{c}\text { CPP } \\
\text { "Komsomolet } \\
\text { s" mine }\end{array}$ & & $\begin{array}{l}\text { CPP "named } \\
\text { after } \\
\text { S.M.Kirov" } \\
\text { mine }\end{array}$ & $\begin{array}{c}\text { CPP } \\
\text { "Komsomole } \\
\text { ts" mine }\end{array}$ \\
\hline $\mathrm{SiO}_{2}$ & 59.83 & 62.06 & $\mathrm{Co}_{2} \mathrm{O}_{3}$ & 0.017 & - \\
\hline $\mathrm{Al}_{2} \mathrm{O}_{3}$ & 21.33 & 20.00 & $\mathrm{BaO}$ & 0.15 & 0.23 \\
\hline $\mathrm{CaO}$ & 4.81 & 4.64 & $\mathrm{C}$ & 0.62 & - \\
\hline $\mathrm{Fe}_{2} \mathrm{O}_{3}$ & 3.20 & 3.61 & $\mathrm{ZnO}$ & 0.019 & 0.023 \\
\hline $\mathrm{Na}_{2} \mathrm{O}$ & 1.58 & 1.70 & $\mathrm{Rb}_{2} \mathrm{O}$ & 0.014 & 0.012 \\
\hline $\mathrm{K}_{2} \mathrm{O}$ & 3.73 & 3.25 & $\mathrm{Cr}_{2} \mathrm{O}_{3}$ & 0.026 & 0.026 \\
\hline $\mathrm{MnO}$ & 0.10 & 0.041 & $\mathrm{SrO}$ & 0.069 & 0.10 \\
\hline $\mathrm{MgO}$ & 1.42 & 1.45 & $\mathrm{TiO}_{2}$ & 0.85 & 0.84 \\
\hline $\mathrm{P}$ & 0.13 & 0.14 & $\mathrm{CuO}$ & 0.14 & 0.016 \\
\hline$S$ & 0.45 & 0.86 & $\mathrm{NiO}$ & 0.031 & 0.018 \\
\hline
\end{tabular}

From X-ray spectral analysis of ash samples (Table 1), obtained after WCF combustion on the basis of FDCWW CPP JSC "SUEK-Kuzbass", it can be seen that these ash is most suitable as an additive to the hardening mixtures used to store the worked out space (high content of silicon oxide and alumina are combined with a low content of $\mathrm{C}$ (carbon), i.e., a negligible unburned carbon loss).

\section{Experimental studies on the preparation of various components of building materials on the basis of the ASW}

Laboratory tests were carried out to assess the possibility of using ash ASW as a component of the filling mixes used to store the worked out space. For this purpose, after a series of WCF combustion on the basis of the FDCWW CPP JSC "SUEK-Kuzbass", samples were taken: from the furnace - ASW, and from the dust collector - fly ash.

The technological scheme of preparation of a back-filling mixture includes the preparation of inert fillers from ASW and kind (granulated slag). Preliminarily ASW are classified according to the $6 \mathrm{~mm}$ class. The screen through of classification is sent to "wet" grinding to class $0-0,200 \mathrm{~mm}$. The ground product is dosed into the mixing apparatus. The over-sized material is added to the crushed rock - granulated slag.

The production of finely ground material based on ash-and-slag wastes was carried out according to the following procedure: the initial samples of the ASW were classified in the $6 \mathrm{~mm}$ class, then the wet grinding of ASW (class $0-3 \mathrm{~mm}$ ) was produced in a vibration chamber (Fig. 1). Before grinding, a sample of ash and slag wastes (class $0-3 \mathrm{~mm}$ ) weighing from 15 to $25 \mathrm{~kg}$ was mixed with water in a ratio of 1: 1 . 


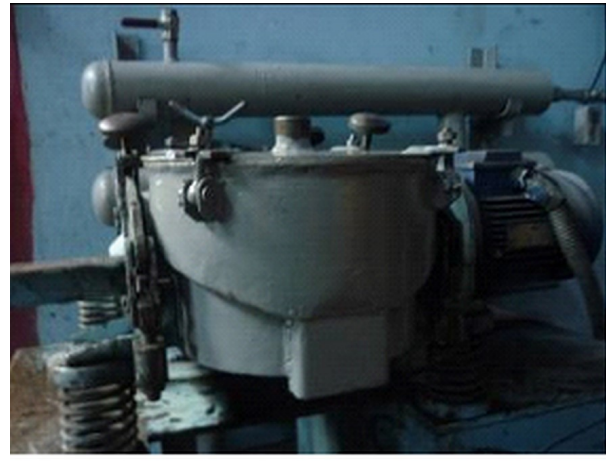

a)

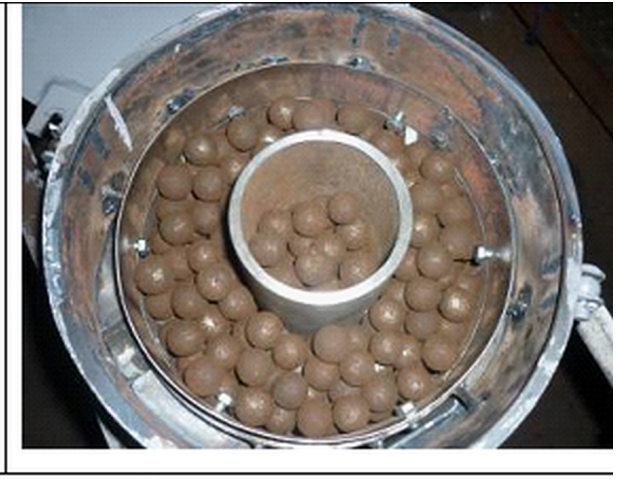

b)

Fig. 1. Vibration chamber: a) - general view; b) top view with cover removed.

For preparing the experimental samples of the hardening tab, the finely ground suspension of the ASW with the water obtained in the vibration chamber was mixed with cement and fillings. As a fillings, we used a screened mixture of ash (class $+6 \ldots+10 \mathrm{~mm}$ ) and kind (granulated slag) (class $+6 \ldots+10 \mathrm{~mm}$ ).

Table 2 shows the ratios of components used in experiments in the filling mixture.

Table 2. The ratio of components in the filling mixture.

\begin{tabular}{|l|c|c|c|c|}
\hline \multirow{2}{*}{$\begin{array}{c}\text { Name of components } \\
\text { (dry weight) }\end{array}$} & \multicolumn{4}{|c|}{ Ratio of components, \% } \\
\cline { 2 - 5 } & Variant 1 & Variant 2 & Variant 3 & Variant 4 \\
\hline Ash-and-slag waste & 31 & 28 & 23 & 18 \\
\hline Kind (granulated slag) & 33 & 33 & 33 & 33 \\
\hline Cement & 6 & 9 & 14 & 19 \\
\hline Water & 30 & 30 & 30 & 30 \\
\hline
\end{tabular}

The prepared mixtures were loaded into molds $(70 \times 70 \times 70)$ and kept for a set strength of 28 days.

Then, the obtained experimental samples were removed from the molds. The extracted experimental samples of the hardening tab are shown in Fig. 2.

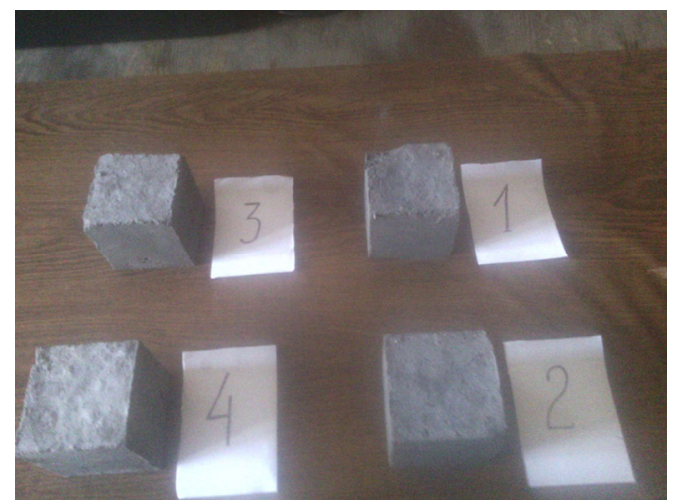

Fig. 2. Experimental samples of the hardening tab.

The 28 days experimental samples were tested for strength in accordance with GOST 21153.2-84. Table 3 presents the results of testing the experimental samples for uniaxial compression strength. 
Table 3. Test results of experimental samples

\begin{tabular}{|l|c|c|c|c|}
\hline \multirow{2}{*}{ Name sample } & \multicolumn{5}{|c|}{ Uniaxial compression strength, depending on the blend } \\
& composition, k·N / MPa & Variant 4 \\
\cline { 2 - 5 } & Variant 1 & Variant 2 & Variant 3 & Variant \\
\hline Filling mixture & $0.76 / 0.084$ & $3.77 / 0.70$ & $11.98 / 2.40$ & $22.17 / 4.5$ \\
\hline
\end{tabular}

Variant №4 of the mixture composition is optimal for the strength characteristics and cement content and corresponds to the required technological parameters. The optimal ratio of the initial components, at which the required strength of hardening samples (more than 4.0 $\mathrm{MPa}$ ) is achieved, of the filling mixture is given in Table 4.

Table 4. The optimum percentage of the initial components of the filling mixture.

\begin{tabular}{|c|c|c|c|c|c|}
\hline Component & ASW & $\begin{array}{c}\text { Kind (granulated } \\
\text { slag) }\end{array}$ & Cement & Water & $\begin{array}{c}\text { Filling } \\
\text { mixture }\end{array}$ \\
\hline Content, \% & 18 & 33 & 19 & 30 & 100,0 \\
\hline
\end{tabular}

\section{Conclusion}

1. A boiler with a vortex combustion system of WCF prepared on the basis of the FDCWW CPP Kuzbass mines was designed, manufactured and tested.

2. During the work, a study was made of the mineralogical composition of ASW and the composition of the ash obtained after burning the filter cake samples. The optimum percentage ratio of the initial components of the filling mixture prepared on the basis of the ASW and rock was established. It is determined that the ash data is most suitable as an additive in the hardening mixtures used to store the worked out space (the high content of silicon oxide and aluminum oxide is combined with a low carbon content, i.e., a negligible unburned carbon loss).

3. The results of experimental samples tests for strength on uniaxial compression are obtained. It has been established that the sample containing $18 \%$ of ash, $19 \%$ of cement and $33 \%$ of crushed rock corresponds to the required technological parameters according to the characteristics of strength and cement content.

\section{Acknowledgement}

The study was carried out with the financial support of the Russian Foundation for Basic Research, the Government of the Krasnoyarsk Territory, the Krasnoyarsk Regional Foundation for the Support of Scientific and Technological Activities "within the framework of the scientific project No 17-48-240386 p_a.

\section{References}

1. E. I. Wan, M. D. Fraser, C. N. Logan, Proceedings of the IEA-CLM, 22, 00879 (1993)

2. R. A. Ashworth, T. A. Melick, D. K. Morrison, J. J. Battista Twenty Third International Technical Conference on Coal Utilization \& Fuel Systems (Coal \& Slurry Technology Association and ASME-FACT, Clearwater, 1998)

3. J. D. Morrison, A. W. Scaroni, J. J. Battista, XIII International Coal Preparation Congress (ICPC, Brisbane, 2012) 
4. A. M. Musalam, A. Fattah, A. Qaraman. International Journal of Energy and Environmental Research, 4(3), 27 (2010)

5. V. I. Murko, V. I .Karpenok, Yu. A. Senchurova, V. A. Khyamyalyainen, O. V. Tailakov, Coal in the 21st Century: Mining, Processing and Safety, 297 (2016)

6. V. Murko, V. Hamalainen, E3S Web of Conferences, 21, 01029 (2016)

7. V. I. Murko, V. I. Karpenok, V. I. Fedyaev, E. M. Puzyryov, M. P. Baranova, XVIII International Coal Preparation Congress Conference proceedings, 345 (2016) 